\title{
Regional carbon isotope syntheses from the last deglaciation
}

\author{
Andreas Schmittner ${ }^{1}$, G. Martínez-Méndez², A.C. Mix ${ }^{1}$ and J. Repschläger ${ }^{3}$ \\ Corvallis, USA, 27-29 June 2017
}

The last deglaciation, which is Earth's climatic transition from the Last Glacial Maximum (LGM, 21 ka BP) to the Holocene (current interglacial period; 10 ka BP), is still not fully understood. The associated rise in atmospheric $\mathrm{CO}_{2}$ and related changes in ocean circulation and carbon storage remain puzzling. Carbon isotopes $\left(\delta^{13} \mathrm{C}\right)$ are influenced by ocean circulation and carbon cycling, including the biological pump and air-sea gas exchange, and preserved in the sedimentary record in fossil shells of benthic foraminifera (unicellular organisms living at the sea floor). The PAGES working group Ocean Circulation and Carbon Cycling (OC3) aims to synthesize benthic $\delta^{13} \mathrm{C}$ sediment data globally to reconstruct and understand the mechanism of natural climate and carbon cycle changes with a focus on the last deglaciation.

The current, second OC3 phase focuses on down-core data syntheses in different ocean basins (Fig. 1). Goals of this second OC3 workshop were to discuss the progress and first analyses of the data collection, issues of database structure, scientific questions, and possible publications. Talks presented new modeling results on changes in meltwater fluxes during the last deglaciation, and effects of their spatial distribution on ocean circulation. Model results also explored connections between the Atlantic Meridional Overturning Circulation (AMOC), deep ocean carbon storage and isotope distributions, and atmospheric $\mathrm{CO}_{2}$. A presentation on age-model uncertainty showed differences of more than 1,000 years depending on the method used to construct the age model (radiocarbon versus oxygen-isotope alignment versus surface-property alignment). Down-core data from the North Atlantic raised the question of northern versus southern sources for reconstructed, very depleted $\delta^{13} \mathrm{C}$ and $\delta^{18} \mathrm{O}$ deep water (Repschläger et al. 2015; Keigwin and Swift 2017), whereas negative $\delta^{13} \mathrm{C}$ excursions in intermediate waters may be explained by changes in the efficiency of the biological pump (Lacerra et al. 2017).

Presentations on Pacific Ocean syntheses showed that the water-mass geometry in the southeast Pacific did not substantially change during the LGM and suggested larger than previously thought mean-ocean $\delta^{13} \mathrm{C}$ change during the deglaciation, which may challenge existing interpretations about changes in terrestrial carbon storage. A decoupling of the Pacific from the Atlantic circulation during the LGM was suggested by a comparison of $\delta^{13} \mathrm{C}$ depth transects from the southwest Pacific and the southwest Atlantic. The single presentation about the Indian

\section{Core depth (m)}

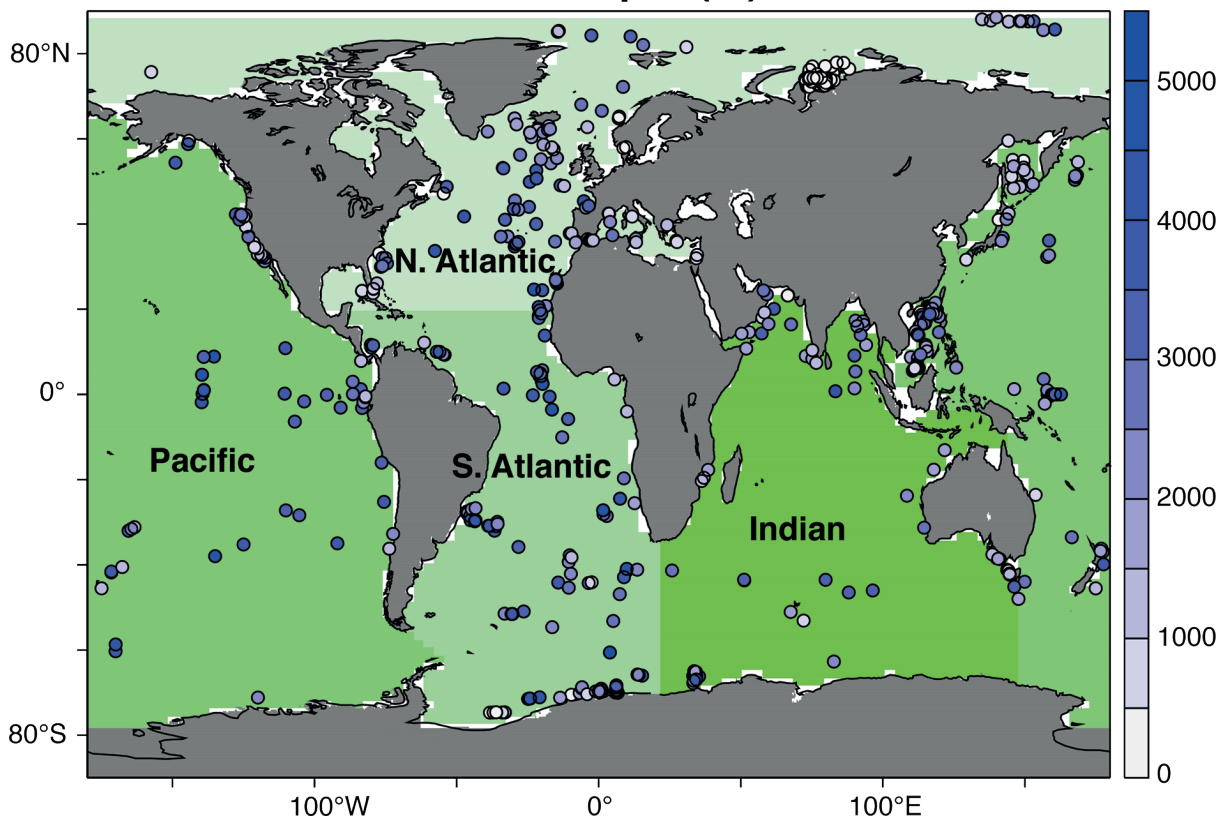
ses and one global synthesis paper. The next and final OC 3 meeting will be in Cambridge, UK, from 13-16 September 2018, preceded by informal meetings at the AGU Fall and Ocean Sciences meetings.

\section{AFFILIATIONS}

'College of Earth, Ocean, and Atmospheric Sciences, Oregon State University, Corvallis, USA

${ }^{2}$ MARUM-Center for Marine Environmental Science, University of Bremen, Germany

${ }^{3}$ Department Climate Geochemistry, Max-Planck Institute for Chemistry, Mainz, Germany

\section{CONTACT}

Andreas Schmittner: aschmitt@coas.oregonstate.edu REFERENCES

Keigwin LD, Swift SA (2017) PNAS 114: 2831-2835 Lacerra M et al. (2017) Paleoceanogr 32: 780-795 Repschläger J et al. (2015) Paleoceanogr 30: 456-476 